\title{
The Diet of the Yuanmou Hominoid, Yunnan Province, China: An Analysis from Tooth Size and Morphology
}

\author{
Liu $\mathrm{Wu}^{1}$, Gao Feng ${ }^{2}$, and Zheng Liang ${ }^{2}$ \\ ${ }^{1}$ Institute of Vertebrate Paleontology and Paleoanthropology, Chinese Academy of Sciences, Beijing, \\ China \\ ${ }^{2}$ Yunnan Provincial Institute of Archaeology, Kunming, China
}

(Received July 9, 2001; accepted February 13, 2002)

\begin{abstract}
In the past decades numerous late Miocene hominoid fossils have been discovered in Eurasia but the relationships among them and to the later hominids are still in debate. Yunnan Province of China is one of the key places of hominoid fossil discoveries. Till now, four sites have yielded Miocene hominoid fossils. Among them, Lufeng and Yuanmou rank with Siwalik as the richest fossil sites in Eurasia. Here, we report the results of a dietary analysis of the Yuanmou hominoid. Our analyses of tooth size proportions, $\mathbf{M}_{2}$ shearing crest development, tooth enamel thickness and body weight of Yuanmou and other Miocene hominoids indicate that, compared with other samples, the Yuanmou hominoid had relatively bigger front teeth and weakly developed molar shearing crests (lower SQ). So, the Yuanmou hominoid is considered to have mainly fed on a harder or frugivorous diet. Among the other Miocene hominoids considered in present study, the SQs of Proconsul nyanzae, Ouranopithecus macedoniensis, Dendropithecus macinnesis and Lufengpithecus lufengensis is close to that of Yuanmou indicating that they had similarly developed molar shearing crests with a likely preference for hard fruits. On the other hand, there are some differences between the Yuanmou hominoid and Lufengpithecus in all the four aspects of evidence studied here. Among them, Lufengpithecus had relatively smaller front teeth, relatively smaller $\mathrm{M}^{1}$, higher SQ, indicating that more folivorous and soft dietary items like leaves and berries were consumed. The preferred paleoenvironments of the Yuanmou hominoid and Lufengpithecus might also have been different.
\end{abstract}

Keywords: Miocene hominoid, diet, tooth size, tooth morphology, Yuanmou hominoids

\section{Introduction}

Hominoid primates are known from the Miocene to the present. Among them, ape-like primates from the middle to late Miocene of Eurasia have been discovered since more than a century ago and new finds continue to improve the record of those important taxa (Pilbeam, 1997). In south Asia, besides the finding of Sivapithecus in

Corresponding author: Liu $\mathrm{Wu}$

Institute of Vertebrate Paleontology and Paleoanthropology, Chinese Academy of Sciences

P.O. Box 643, Beijing 100044, China

E-mail: liu.wu@pa.ivpp.ac.cn or liuwu@mx.cei.gov.cn 
Indo-Pakistan, the most important event of late Miocene hominoid fossil finding came from the Yunnan Province of China. Till now, hominoid fossils have been found from four sites, Kaiyuan (Keiyuan), Lufeng, Baoshan and Yuanmou, in Yunnan Province (Zheng and Zhang, 1997). Among them, except that the Baoshan site in the western part of Yunnan Province, where a hominoid mandible was found in 1992, is less known and has no formal publication, many studies of hominoid fossils, mammal fauna, chronology and other related topics for the three other sites have been carried out. In Kaiyuan, following the ten teeth found in the 1950's, some more fossils were unearthed in the 1980's including 3 lower molars in 1980 and a maxillary bone attached with 12 teeth in 1982 (Woo, 1957, 1958; Zhang, 1987). Based on mammal fauna analysis, the date of the Kaiyuan hominoid has been proposed as early Pliocene or middle Miocene (Woo, 1957; Zheng and Zhang, 1997). In his original studies of the ten teeth, Woo found some similarities between Kaiyuan specimens and those of Dryopithecus punjabicus, and classified the Kaiyuan teeth into Dryopithecus keiyuanensis. With the analyses of the new specimens, Zhang put the Kaiyuan fossils into Ramapithecus keiyuanensis as a taxon ancestral to Lufengpithecus (Zhang, 1987). From 1975-1983, a series of excavations were carried out in Lufeng, a late Miocene hominoid site, where five skulls, tens of mandibles, hundreds of isolated teeth and some post -cranial bones were found. After several year's studies, Wu (Woo) classified Lufeng fossils as Lufengpithecus lufengensis and proposed that Lufengpithecus might be the ancestor of both African apes and hominids (Wu, 1987). However, some other colleagues still hold different opinions (Schwartz, 1997). The relationship to each other for Lufengpithecus and "Dryopithecus keiyuanensis" "to other Neogene hominoids, and to extant apes are all unclear" (Pilbeam, 1997). Because of these reasons, the newly found Yuanmou hominoid fossils are especially important. The Yuanmou hominoid fossils were first found in 1986, when an upper molar was unearthed near Zhupeng village. From 1987 to 2000, several field survey and excavations were organized by the Institute of Vertebrate Paleontology and Paleoanthropology, Chinese Academy of Sciences and Yunnan Provincial Institute of Archaeology (formally Provincial Museum). Three hominoid fossil-bearing sites (Xiaohe, Zhupeng and Leilao) were found within 10 kilometers distance from each other. Till now, a big collection of fossils including a virtually complete juvenile cranium, several jaw bones and over 1,500 isolated teeth have been recovered (He, 1997). According to the mammalian fauna and paleomagnetic analysis, the hominoid fossils probably came from the late Miocene deposits (about 8 mya). So far, the studies of the Yuanmou hominoid fossils (Zheng and Zhang, 1997; Liu et al., 2000; Liu et al., 2001a; Liu et al., 2001b; Schwartz et al., 2002) indicate that the Yuanmou hominoid is more similar to Lufengpithecus and the orangutan than to any other fossil and extant large-bodied hominoid. However, as mentioned above, the precise relationship of these late Miocene hominoids to extinct and extant great apes is still 
a subject of controversy, with various authors suggesting affinities of Lufengpithecus with the Sivapithecus-orangutan radiation, African apes or representing the last common ancestor of all extant great apes. Thus, the phylogenetic position of Lufengpithecus, and consequently the Yuanmou fossil material, is still in debate (Zheng and Zhang, 1997; Liu et al., 2001b).

In the research of Miocene hominoid and early hominid evolution, the role of diet has received much attention. The diet of hominoids and early hominids are closely related to their body size, mastication, ingestion and locomotor behaviors. Also, the analysis of diet can provide information on paleoenvironments, population structure and geographic distributions of the Miocene hominoids (Walker, 1981). Most of the evidence for diet comes from five sources: analysis of tooth size, tooth shape, enamel structure, dental microwear and jaw biomechanics (Teaford and Ungar, 2000). Studies of the relationship between diet and tooth size show that those species with larger incisors tend to consume larger, tougher fruits, whereas those with smaller front teeth tend to feed on smaller-sized food, or those that require less extensive incisal preparation, such as leaves or berries (Hylander, 1975). The ratio of the areas of M1 and M3 is inversely related to the percentage of leaves, flowers and shoots. Anthropoids with a high ratio of M1 to M3 area tend to consume more fruit than those with a low M1 to M3 ratio (Lucas, Corlett and Luke, 1986). For tooth shape, several researchers have demonstrated the relationship between diet and the development of shearing blades on molar teeth of living catarrhines (Kay, 1981, 1984; Ungar and Kay, 1995). Folivorous apes, for example, show relatively longer shearing crests than do frugivorous ones. The shearing quotient (SQ) was designed to indicate the development of molar shearing crests (Ungar and Kay, 1995; Kay and Ungar, 1997). Basically, the more folivorous species have the highest SQ, followed by those that prefer soft fruits. Finally, hard-object feeders have the lowest SQ. In addition, enamel thickness, microwear, and mandibular biomechanics are also helpful in evaluating diet (Andrews and Martin, 1991; Martin, 1985; Ungar, 1996). As mentioned above, even though the Yuanmou hominoid fossils have been found since more than ten years ago, the studies of these fossils have been mainly focused on the descriptions of cranial and dental morphologies. Little attention has been paid to the topics of diet, ecology and paleoenvironments of the Yuanmou hominoid, which, to a great extent, limits a fuller understanding of the whole characteristics and phylogenetic affinities of the Yuanmou hominoid. In this study, we examine tooth size proportions, molar shearing crest development, enamel thickness and body weight of the Yuanmou hominoid, trying to infer its diet and paleoenvironments.

\section{Material and Methods}

In the present study, we used the Yuanmou hominoid teeth to collect four aspects of data to study the food preference of this Miocene hominoid. 
Table 1. The lower second molars of the Yuanmou hominoid and Lufengpithecus used for shearing crest analysis in the present study

\begin{tabular}{|c|c|c|c|}
\hline \multicolumn{2}{|c|}{ Yuanmou hominoid } & \multicolumn{2}{|c|}{ Lufengpithecus } \\
\hline Specimen number & Side & Specimen number & Side \\
\hline B 3.12 & right & L 53 & right \\
\hline F. .24 & left & L 509 & right \\
\hline F 4.35 & right & L 510 & left \\
\hline F. .5 & right & L 511 & right \\
\hline F .8 & right & L 579 & right \\
\hline F.83 & left & L 580 & right \\
\hline PDYA 12 & left & L 583 & left \\
\hline YV 1316 & left & L 588 & left \\
\hline YV 1341 & left & L 589 & right \\
\hline YV 1381 & left & L 623 & left \\
\hline YV 1395 & left & L 624 & right \\
\hline YV 1403 & right & L 687 & left \\
\hline YV 1616 & right & No number & right \\
\hline YV 1691 & left & & \\
\hline YV 1693 & left & & \\
\hline YV 1697 & right & & \\
\hline YV 1832 & right & & \\
\hline YV 1913 & left & & \\
\hline YV 2130 & left & & \\
\hline YV 2143 & right & & \\
\hline YV 2151 & left & & \\
\hline YV 2505 & right & & \\
\hline YV 2507 & left & & \\
\hline YV 2514 & right & & \\
\hline
\end{tabular}

Tooth size proportions: Two ratios of tooth sizes were calculated to infer the relationship between front and rear tooth sizes, and between the sizes of $\mathrm{M}^{1}$ and $\mathrm{M}^{3}$. The two ratios are (1) the comparison of mesiodistal length of the upper central incisor with that of the first upper molar $\left(\mathrm{I}^{1} / \mathrm{M}^{1}\right)$; (2) the ratio of the crown areas (mesiodistal lengths $\times$ buccolingual lengths) of $\mathrm{M}^{1}$ and $\mathrm{M}^{3}$. All the teeth of the Yuanmou hominoid used for size proportion analyses in the present study are isolated teeth and were measured by the first author. The raw data and the details of the provenience were published in a separate paper (Liu, Zheng and Jiang, 2000).

$\mathbf{M}_{2}$ shearing crests and SQ: From the fossil collection housed in the Yunnan Provincial Institute of Archaeology, we chose 24 Yuanmou hominoid and 13 Lufengpithecus lower second molars. All the teeth are in relatively good preserved condition, and were unworn or nearly unworn. Table 1 gives further detailed information for these teeth. 
Following the method set forth by Kay and Ungar (Kay, 1984; Ungar and Kay, 1995; Kay and Ungar, 1997), under a binocular microscope with graduated scales, we observed and measured the lengths of eight shearing crests of the 24 Yuanmou hominoid and 13 Lufengpithecus $\mathbf{M}_{2}$. We then summed the eight lengths to get total shear $\left(\mathrm{T}_{\text {shear }}\right)$. Using $\mathrm{M}_{2}$ lengths and shearing crest data of extant frugivorous species, Kay and Ungar established a regression line.

\section{$\log _{10}$ total shear $=\log _{10} \mathrm{M}_{2}$ length $\times 0.959+0.386$}

They suggested that the Miocene hominoid fossil data can be adequately evaluated with reference to this line because frugivores span practically the entire range of size for the extant hominoids and also because there are more extant frugivores than folivores. This regression can be used to predict shearing crest lengths expected of a frugivorous ape with a given mesiodistal $\mathrm{M}_{2}$ length. The shearing quotient (SQ) is obtained from the difference between observed and expected crest lengths.

$\mathrm{SQ}=100 \times($ observed-expected $) /$ expected shearing crest lengths

Because the SQ is based on the regression of extant frugivorous species, a positive SQ indicates relatively long shearing crests such as for the folivorous primates; a negative SQ denotes less developed shearing crests than for a typical frugivourous taxa. In this study, we used the above equations and calculated total shear and SQ for the Yunamou hominoid. We also measured 13 Lufengpithecus $\mathrm{M}_{2} \mathrm{~S}$ to get comparable data for comparison. The other comparative data were cited from Kay and Ungar (1997).

Enamel thickness: The enamel thickness data of the Yuanmou hominoid was acquired by sectioning one lower molar and was reported in a previous study (Schwartz et al., 2002).

Body weight estimation: Two regression equations, by Gingerich (1977) and Conroy (1987), were used to estimate body weight of the Yuanmou hominoid. The body weight of Lufengpithecus and "Dryopithecus keiyuanensis" were also estimated.

Gingerich's regression: $\log _{10}$ (body weight $)=2.99 \log _{10}\left(M_{2}\right.$ length $)+1.46$

Table 2. Mean values of some tooth data of Yuanmou hominoid, Lufengpithecus and "Dryopithecus keiyuanensis" (in mm)

\begin{tabular}{lcccccc}
\hline & $\mathrm{I}^{1}$ length & $\mathrm{M}^{1}$ length & $\mathrm{M}^{1}$ area & $\mathrm{M}^{3}$ area & $\mathrm{M}_{2}$ length & $\mathrm{M}_{1}$ area \\
\hline Yuanmou & $9.2(79)$ & $9.8(110)$ & $108.4(110)$ & $112.5(82)$ & $11.9(110)$ & $98.3(86)$ \\
\hline Lufeng & $9.9(47)$ & $11.1(41)$ & $134.3(41)$ & $160.9(23)$ & $13.4(62)$ & $120.5(42)$ \\
\hline Kaiyuan & - & - & $105.0(1)$ & $110.2(1)$ & $12.5(4)$ & $113.1(2)$ \\
\hline
\end{tabular}

Data in parentheses are sample sizes 
Conroy's regression: $\log _{\mathrm{e}}($ body weight $)=1.572 \log _{\mathrm{e}}\left(\mathrm{M}_{1}\right.$ area $)+3.39$

The tooth size data used in calculating the body weights were taken from the dental metric studies of the Yuanmou hominoid, Lufengpithecus and "Dryopithecus keiyuanensis" (Liu et al., 2000; Wood and Xu, 1991; Woo, 1957, 1958; Zhang, 1987) respectively. All the tooth data used to calculate body weight are mean values.

Table 2 lists the mean values of some tooth data used in calculating tooth size proportion and body weights for Yuanmou hominoid, Lufengpithecus and "Dryopithecus keiyuanensis".

\section{Results and Discussion}

\section{Tooth size proportions}

Table 3 lists the ratio $\mathrm{I}^{1} / \mathrm{M}^{1}$ of the Yuanmou hominoid and some of the fossil and extant hominoids. From the data in Table 3, we can find that the ratio of $\mathrm{I}^{1} / \mathrm{M}^{1}$ of the Yuanmou hominoid (0.94) is closer to those of Proconsul, Afropithecus, Ankarapithecus and Sivapithecus (0.93-0.98), and exceeds the same ratio of Lufengpithecus, Dryopithecus and Ouranopithecus (0.77-0.89), indicating the former taxa have relatively larger upper incisors and thus a more frugivorous diet. The ratio of Australopithecus is also small $(0.60-0.89)$. These comparisons clearly indicate that relative front tooth size of the Yuanmou hominoid is bigger than that of Lufengpithecus.

The comparison of $\mathrm{M}^{1}$ and $\mathrm{M}^{3}$ areas in Figure 1 indicates that among the fossil

Table 3. Comparisons of mesiodistal lengths of $\mathrm{I}^{1}$ with $\mathrm{M}^{1}\left(\mathrm{I}^{1} / \mathrm{M}^{1}\right)$

\begin{tabular}{lccr}
\hline \multicolumn{1}{c}{ Taxon } & Means & Ranges & $N$ \\
\hline Yuanmou hominoid* & 0.94 & & \\
Lufengpithecus $^{*}$ & 0.89 & & 16 \\
Orangutan & 1.13 & $0.95-1.22$ & 8 \\
Chimpanzee & 1.09 & $0.95-1.24$ & 12 \\
Gorilla & 0.90 & $0.84-0.96$ & 3 \\
Proconsul & 0.93 & $0.90-0.98$ & 1 \\
Afropithecus & 0.98 & & 1 \\
Sivapithecus & 0.98 & & 2 \\
Ankarapithecus meteai & 0.96 & $0.93-0.99$ & 2 \\
Ouranopithecus & 0.80 & $0.77-0.82$ & 1 \\
Dryopithecus & 0.81 & & 3 \\
Australopithecus africanus & 0.81 & $0.76-0.89$ & 2 \\
Australopithecus afarensis & 0.89 & $0.86-0.93$ & 1 \\
Paranthropus boisei & 0.60 & & \\
\hline
\end{tabular}

Data other than for the Yuanmou hominoid are cited from Andrews and Martin (1991), Alpagut et al. (1996) for Ankarapithecus meteai, and Wood and Xu (1991) for Lufengpithecus. *The Yuanmou hominoid and Lufengpithecus values were calculated from mean values of isolated $\mathrm{I}^{1} \mathrm{~s}$ and $\mathrm{M}^{1} \mathrm{~s}$. 
taxa, the hominoids from Yuanmou and Kaiyuan ranked with Dryopithecus having relatively bigger $\mathrm{M}^{1}$ than all other Miocene hominoids including Lufengpithecus. This suggests that the former group have a more frugivorous diet than the latter. Also, among the three Chinese hominoid assemblages, Yuanmou and Kaiyuan have relatively bigger $\mathrm{M}^{1}$ than Lufengpithecus, suggesting that a more folivorous diet was consumed by Lufengpithecus.

With regards to the relationship between tooth size proportions and diet, both Hylander and Kay found a high correlation between relative size of incisor and diet (Hylander, 1975; Kay, 1984, 1985). Those species with larger incisors tend to consume larger, tougher fruits, whereas those with smaller front teeth tend to feed on smaller food, or those that require less extensive incisal preparation, such as leaves or berries. The main reason for this relationship is that the front teeth (the incisors, and to some extent the canines) are modified for obtaining food, and the cheek teeth are designed for effective chewing before swallowing (Hylander, 1975; Kay, 1984). This phenomenon was found quite clearly expressed in Australopithecus and has been used to infer their diet (Kay, 1985; Teaford and Ungar, 2000). Unfortunately, till now, not much has been done to study the diets of Miocene hominoids from relative incisor size. Our comparison shows that the Yuanmou hominoid is closer to Proconsul, Afropithecus, Ankarapithecus and Sivapithecus in having relatively big-

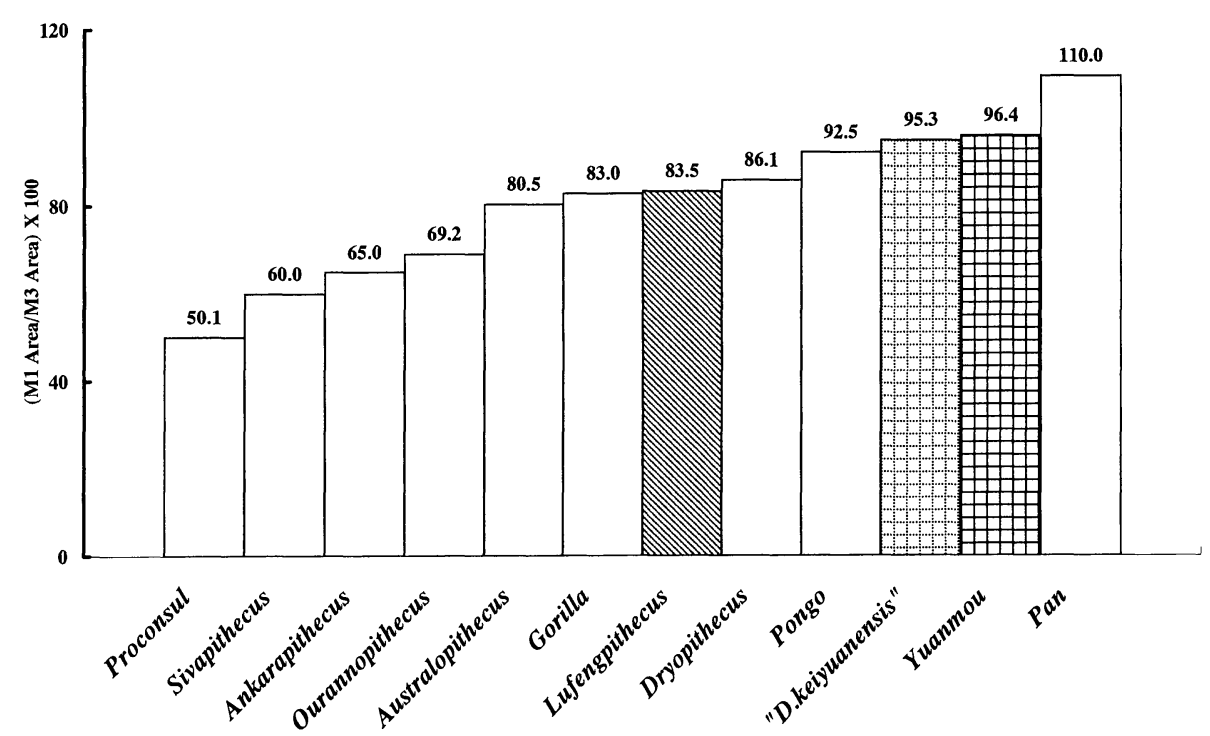

Figure 1. Ratios of $\mathrm{M}^{1}$ to $\mathrm{M}^{3}$ area. Data other than for the Yuanmou hominoid, Lufengpithecus (Wood and Xu, 1991), and “D. keiyuanensis" (Zhang, 1987) are cited from Teaford and Ungar (2000). 
ger incisors than those of Lufengpithecus, Dryopithecus and Ouranopithecus suggesting the former should feed on tougher food than latter group members.

Another tooth size proportion factor related to diet discussed in the present study is the ratio of $\mathrm{M}^{1} / \mathrm{M}^{3}$ areas. The study by Lucas and his colleagues (Lucas et al., 1986) based on 69 anthropoid primates demonstrated that the ratio of $\mathrm{M}^{1} / \mathrm{M}^{3}$ areas is inversely related to the percentage of leaves, flowers, and shoots in the diet, which means that anthropoids with a high ratio of $\mathrm{M}^{1}$ to $\mathrm{M}^{3}$ areas consume more fruits than those with a low $M^{1}$ to $M^{3}$ ratio. With this principle in mind, we calculated the $M^{1} / M^{3}$ area ratio for the Yuanmou hominoid and compared it with some of the living and fossil primates. Fig. 1 shows that compared with Australopithecus and the other fossil great apes, the Yuanmou hominoid, "Dryopithecus keiyuanensis" (the ratio for Yuanmou is 0.964 and for Kaiyuan is 0.953 ) and Dryopithecus have relative bigger $\mathrm{M}^{1}$ than Lufengpithecus (with ratio of 0.835 ) and other taxa. This result further supports the finding from the $\mathrm{I}^{1} / \mathrm{M}^{1}$ length ratio that the Yuanmou hominoid may have fed on harder food than Lufengpithecus, the latter possibly with a more folivorous diet.

\section{$\mathrm{M}_{2}$ shearing crests}

Table 4 displays descriptive statistics of $\mathrm{M}_{2}$ lengths and total shear for the Yuanmou hominoid, Lufengpithecus and some fossil and extant hominoids. The data in Table 4 show that the SQs for Miocene hominoid $\mathrm{M}_{2}$ range from $-13.4-+34.99$, with the highest SQ of 34.99 for Oreopithecus and the lowest SQ of -13.4 for the Yuanmou hominoid, indicating the former has highly developed shearing crests and mainly fed on a folivorous or soft diet like leaves and berries; the latter has less developed shearing crests and mainly ate hard fruits.

Our analysis shows that the SQ values of the Yuanmou hominoid and Lufengpithecus are -13.4 and -4.7 respectively, ranking in the lowest level with Dendropithecus, Proconsul and Ouranopithecus among the Miocene hominoids compared in the present study. These data indicate that the Yuanmou hominoid and Lufengpithecus mainly ate hard-object food. Moreover, the SQ of the Yuanmou hominoid is lower than that of Lufengpithecus suggesting that more folivorous food components like leaves and beries were consumed by Lufengpithecus than by the Yuanmou hominoid. This fits with the findings of the $\mathrm{I}^{1} / \mathrm{M}^{1}$ length and $\mathrm{M}^{1} / \mathrm{M}^{3}$ area comparisons mentioned above.

Compared with incisors, the function of molars is mainly in mastication. From this point, molar morphology generally provides a better guide to dietary adaptation than incisor structure. Several studies have demonstrated a close relationship between diet and the development of shearing blades on molar occlusal surfaces of living primates (Kay, 1984; Kay and Ungar, 1997). Folivorous apes have relatively long shearing crests compared to frugivorous ones, because "leaf fibers form resistant, almost two-dimensional sheets and rods more easily broken by shearing than by 
Table 4. $\mathrm{M}_{2}$ length and shearing-crest statistics

\begin{tabular}{lrrrrrrr}
\hline \multirow{2}{*}{ Samples } & & \multicolumn{2}{c}{$\mathrm{M}_{2}$ crown length } & \multicolumn{2}{c}{ Observed $\mathrm{T}_{\text {shear }}$} & \multirow{2}{*}{ SQ (\%) } \\
\cline { 3 - 6 } & & Mean & SD & Mean & SD & \\
\hline Yuanmou & 24 & 12.6 & 1.22 & 23.9 & 1.73 & -13.4 \\
Lufengpithecus lufengensis & 13 & 14.5 & 0.38 & 30.1 & 1.54 & -4.7 \\
Dendropithecus macinnesis & 7 & 7.05 & 0.20 & 14.63 & 0.75 & -7.57 \\
Proconsul nyanzae & 6 & 10.94 & 0.71 & 21.96 & 1.86 & -8.96 \\
Rangwapithecus gordoni & 6 & 8.69 & 0.33 & 19.29 & 0.33 & -0.27 \\
Dryopithecus laietanus & 5 & 10.50 & 0.39 & 22.94 & 0.94 & -1.08 \\
Oreopithecus bambolii & 2 & 9.88 & - & 29.53 & - & +34.99 \\
Ouranopithecus macedoniensis & 2 & 15.94 & - & 31.69 & - & -8.43 \\
Pliopithecus (Spain) & 2 & 6.00 & - & 14.53 & - & +7.16 \\
Pongo pygmaeus & 5 & 12.77 & 0.92 & 28.98 & 1.92 & +3.58 \\
Pan troglodytes & 10 & 11.68 & 1.05 & 24.74 & 1.84 & -3.68 \\
Gorilla gorilla & 14 & 18.25 & - & 41.95 & - & +6.46 \\
Hylobates syndactylus & 6 & 8.71 & 0.63 & 20.49 & 1.30 & +5.70 \\
\hline
\end{tabular}

Data other than those of Yuanmou and Lufengpithecus were taken from Kay and Ungar (1997)

crushing, whereas frugivores consume more crushable three-dimensional fruits" (Ungar and Kay, 1995). Kay devised a "shearing quotient (SQ)" as a measure of the relative development of shearing crests on molar teeth (Kay, 1984). Basically, more folivorous species have the highest SQ values, followed by those species that feed on brittle, soft fruits; Whereas the hard-object feeders have the lowest SQ. Kay and Ungar's studies indicate that in living great apes, gorilla has the highest SQ indicating highly developed shearing crest and folivorous diet. The lower SQ values of chimpanzee and gibbon fit to their less developed shearing crests and frugivorous food. The Asian orangutan stays between the two and feed on more leaves. For Miocene apes, the diets show a wide range of adaptations, including folivery, soft-fruit, and hard-object feeding. For example, Oreopithecus and Pliopithecus have highly developed shearing crests indicating soft leaf food; Dendropithecus, Proconsul, Ouranopithecus have short shearing crests and low SQ values suggesting frugivorous diets. Dryopithecus and Rangwapithecus were placed in between (Ungar and Kay, 1995; Kay and Ungar, 1997).

In this study, we found that the SQ values of $\mathrm{M}_{2}$ of the Yuanmou hominoid and Lufengpithecus are closer to the SQs of Dendropithecus, Proconsul and Ouranopithecus. All of them belong to the category of less developed shearing crests and mainly feed on hard fruit food. The SQ of Lufengpithecus is bigger than that of the Yuanmou hominoid indicating some differences of shearing crests and diet between the two taxa, with more leaves likely to have been consumed by Lufengpithecus. This fits well with the findings from the analyses of tooth size proportions performed in this 


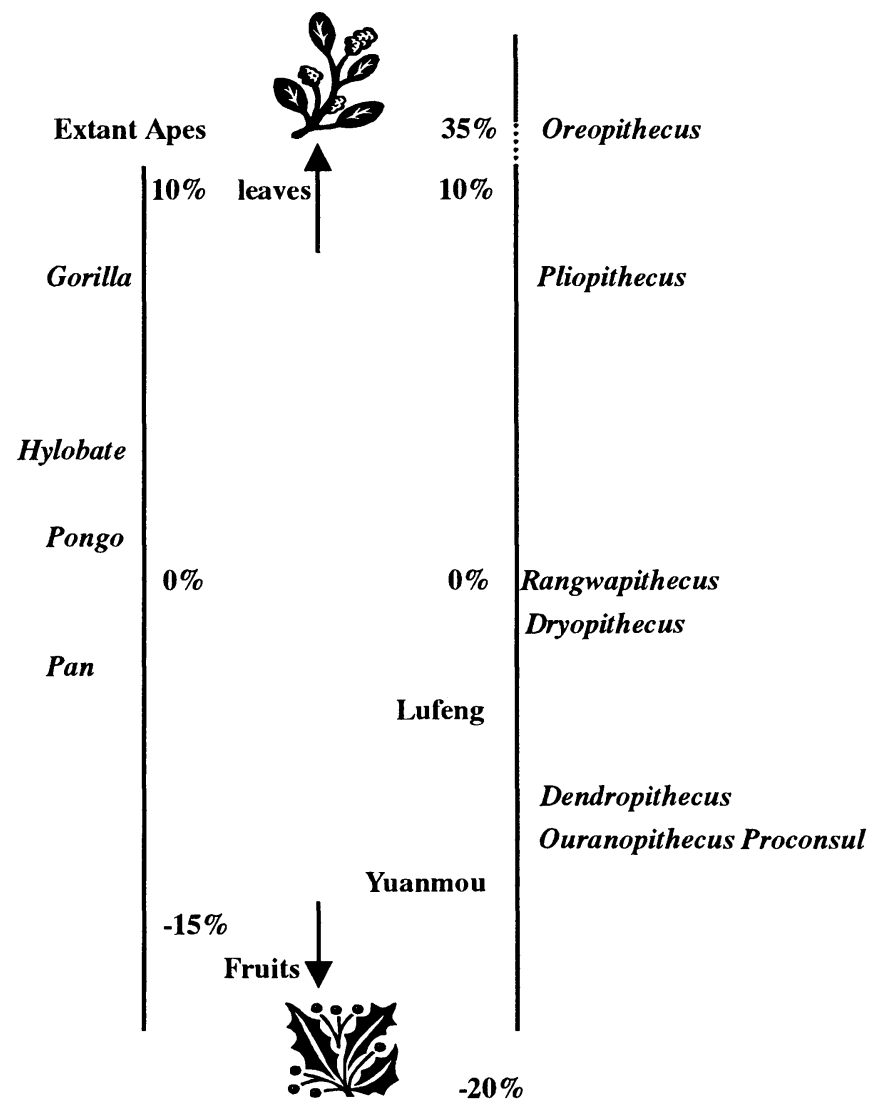

Figure 2. Relative shearing-crest development and possible diets.

study. Fig. 2 displays the relative shearing-crest (SQ) development and possible diets for the Yuanmou hominoid, Lufengpithecus, and other comparative samples.

\section{Enamel thickness}

A dental microstructure study of the Yuanmou hominoid, based on a section of one lower molar, revealed the relative enamel thickness of the Yuanmou molar to be 14.13 (Schwartz et al., 2002), belonging to the intermediate/thin category of enamel thickness according to Martin's criterion (Martin, 1985). The comparative data in Table 5 show that relative enamel thickness of the Yuanmou hominoid is more similar to certain proconsulids (Proconsul major and Rangwapithecus), Oreopithecus and Pongo than it is to Lufengpithecus (24.18), modern Homo, early hominins, Sivapithecus and the remaining proconsulids, all of whom possess "thick" to "hyper-thick" enamel. This result seems to be in contrast to the findings of tooth size proportion and shearing crest lengths mentioned above. The traditional view is that thick enam- 
Table 5. Relative enamel thickness in various Miocene and recent hominoids

\begin{tabular}{lcrc}
\hline \multicolumn{1}{c}{ Taxon } & Relative enamel thickness & $N$ & Ranges \\
\hline Proconsul africanus & 8.54 & 1 & - \\
Gorilla gorilla & 10.04 & 17 & $6.75-13.39$ \\
Pan troglodytes & 10.10 & 14 & $7.02-13.31$ \\
Hylobates lar & 11.02 & 1 & - \\
Dryopithecus fontani & 12.74 & 1 & - \\
Proconsul major & 12.84 & 1 & - \\
Yuanmou hominoid & 14.13 & 1 & - \\
Rangwapithecus gordoni & 14.88 & 1 & - \\
Oreopithecus bambolii & 15.46 & 1 & $11.32-20.45$ \\
Pongo pygmaeus & 15.93 & 17 & - \\
Heliopithecus leakeyi & 17.35 & 1 & $14.40-24.40$ \\
Proconsul heseloni & 18.75 & 3 & $16.07-22.68$ \\
Sivapithecus & 19.73 & 3 & $21.27-23.06$ \\
Australopithecus africanus & 22.17 & 2 & $13.76-32.26$ \\
Homo sapiens & 22.35 & 13 & $22.30-27.60$ \\
Proconsul nyanzae & 24.10 & 3 & $24.11-24.55$ \\
Lufengpithecus & 24.18 & 2 & - \\
Graecopithecus freybergi & 28.34 & 1 & - \\
Paranthropus crassidens & 29.61 & 1 & - \\
Paranthropus robustus & 31.32 & 1 & $30.97-38.58$ \\
Paranthropus boisei & 34.91 & 2 & \\
\hline
\end{tabular}

This table is cited from Schwartz, Liu and Zheng (2002). Data other than those of Yuanmou and Lufengpithecus were taken from Martin (1985), Andrews and Martin (1991), and Beynon et al. (1998).

eled primates feed more on hard food.

Moreover, the relative enamel thickness of 24.18 for Lufengpithecus is also not in accordance with its suggested softer and more folivorous food component. Many early studies demonstrated that enamel thickness is highly correlated with dietary preference. More leaf-eating species like siamang and gorilla have thinner enamel than do the more fruit-eating species like chimpanzee and gibbon (Kay, 1985). For fossil species, some authors say the thick enamel of australopithecines suggests that they ate very hard, brittle foods. Some of the Miocene apes also have thick enamel which may also give clues to their diets (Kay, 1984, 1985; Martin, 1985). But this view has been challenged by some new evidence like the thin enamel of Otavipithecus and Ardipithecus (White et al., 1994; Teaford and Ungar, 2000). Also, recent studies indicate that there are many potential complicating factors related with the functional significance of enamel thickness. For example, thick enamel by itself does not necessarily provide protection against hard objects, which may cause fracture of enamel (Pilbeam, 1997; Schwartz, 2000). So, the correlation between enamel thickness and diet may not be a perfect indicator in estimating diet. The authors think that 
in addition to this reason, the sample size is also important. Only one tooth cannot offer reliable dietary information for the Yuanmou hominoid.

\section{Body weight}

Using the two regression equations by Gingerich (1977) and Conroy (1987), we calculated body weight for the hominoids from the three Chinese sites of Yuanmou, Lufeng and Kaiyuan. Lufengpithecus was estimated to have had the biggest body weight of 55.4 and $67.6 \mathrm{~kg}$, followed by Kaiyuan of 50.2 and $54.9 \mathrm{~kg}$. The Yuanmou hominoid had the smallest body weight of 40.2 and $47.4 \mathrm{~kg}$. From the body weight distribution of some Miocene hominoids in Fig. 3, the body weight of three Chinese hominoids can been seen to differ from both Eurasian Miocene hominoids and African fossil apes. The body weights of Yuanmou, Lufeng and Kaiyuan are smaller than those of Sivapithecus and Ouranopithecus. However, they are bigger than those of Kenyapithecus, Afropithecus and Proconsul

Body size can be related with diet in a general way. There is progression upward in size from insectivory in small animals to herbivory in large animals, with frugivory in between (Walker, 1981; Andrews and Martin, 1991). In living primates, the largest primate that has an insectivorous diet has a mass of no more than $250 \mathrm{~g}$, and the smallest living folivorous primate has a mass of $700 \mathrm{~g}$. The body weight estimates for fossil primates can provide information on diet, ecology and intelligence

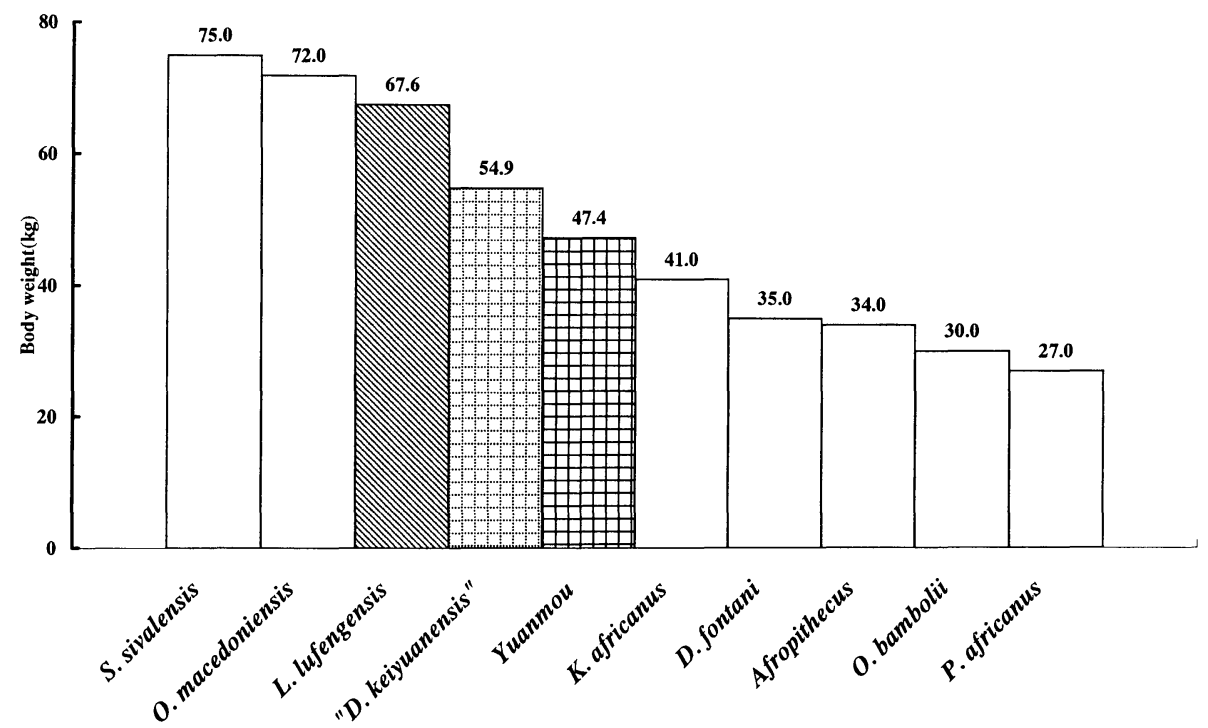

Figure 3. Body weight estimates of some Miocene hominoids Yuanmou, Lufeng and Kaiyuan values were calculated from $\mathrm{M}_{2}$ lengths. Other data are cited from Fleagle (1999) and De Bonis and Koufos (1994). 
levels. Because the primate fossils, especially the great ape fossils, are in most cases fragmentary and isolated teeth occupy great parts of them, the body weight estimates of fossil apes are usually derived from the regression equations based on correlation between tooth size and body weight. The main drawback of this method is that all these equations are established from living primates, and direct application to fossil species may result in some errors because megadonty might have existed in fossil primates, especially in Miocene hominoids. Just for this reason, some authors consider body weights calculated from tooth size to be dubious (Smith, 1996). Despite this, the body weight estimates based on regressions can still reflect the general trends seen in Miocene hominoid body size. The authors believe that the minor differences in body weight among the three Chinese samples may be related to differences in their diets or environments.

\section{Conclusion}

Putting all the evidence analyzed in the present study into consideration, including tooth size proportions, $\mathrm{M}_{2}$ shearing crest development, tooth enamel thickness and body weights, we suggest that the Yuanmou hominoid, with its relatively big front teeth, and weakly developed molar shearing crests (lower SQ), mainly fed on a frugivorous diet. Among all other Miocene hominoids compared in the present study, the SQs of Proconsul nyanzae, Ouranopithecus macedoniensis, Dendropithecus macinnesis and Lufengpithecus lufengensis are closer to that of the Yuanmou hominoid indicating that they have similarly developed molar shearing crests with a dietary preference for hard-object fruits. From these data, we can notice that there are some differences between the Yuanmou hominoid and Lufengpithecus in all four aspects of evidence discussed here. Except for the enamel thickness, the others indicate that Lufengpithecus with its relatively smaller front teeth, smaller $\mathrm{M}^{1}$, and higher SQ, consumed more folivorous and soft dietary items such as leaves, berries (see Fig. 3). The preferred paleoenvironments of the Yuanmou hominoid and Lufengpithecus should also be different.

At present, the analysis of molar shearing crests and dental microwear are two main measures of inferring the diets and ecology of Miocene hominoids. The authors believe that the result of the present study at least offer a general evaluation of the diet of the Yuanmou hominoid. The small sample size of Lufengpithecus as a comparative sample may limit the accuracy of our analysis to some extent. Further use of microwear analysis in the future will offer more reliable evidence for the reconstruction of diet and paleoenvironments of the Yuanmou hominoid.

\section{Acknowledgements}

We wish to express sincere thanks to Dr. Peter Ungar of University of Arkansas for the help of observation and measuring techniques of molar shearing crests. This 
study was supported by National Key Research Project of China (95-01) and National Science Foundation of China (49972011).

\section{References}

Alpagut B., Andrews P., Fortelius M., Kappelman J., Temizsoy I., Celebi H., and Lindsay W. (1996) A new specimen of Ankarapithecus meteai from the Sinap Formation of central Anatolia. Nature, 382: 349-351.

Andrews P. and Martin L. (1991) Hominoid dietary evolution. Philosophical Transactions of Royal Society of London, 334: 199-209.

Beynon A.D., Dean M.C., Leakey M.G., Reid D.J., and Walker A. (1998) Comparative dental development and microstructure of Proconsul teeth from Rusinga Island, Kenya. Journal of Human Evolution, 35: 163-209.

Conroy G.C. (1987) Problems of body-weight estimation in fossil primates. International Journal of Primatology, 8 (2): 115-135.

De Bonis L. and Koufos G.D. (1994) Our ancestors' ancestor: Ouranopithecus is a Greek link in human ancestry. Evolutionary Anthropology, 3: 75-83.

Fleagle G. (1999) Primate Adaptation and Evolution. Academic Press, New York.

Gingerich P.D. (1977) Correlation of tooth size and body size in living hominoid primates, with a note on relative brain size in Aegyptopithecus and Proconsul. American Journal of Physical Anthropology, 47: 395-398.

He Z.Q. (1997) Yuanmou Hominoid Fauna. Yunnan Science Press, Kunming.

Hylander W.L. (1975) Incisor size and diet in anthropoids with special reference to cercopithecidae. Science, 189: 1095-1098.

Kay R. (1981) The nut-crackers - a new theory of the adaptations of the Ramapithecinae. American Journal of Physical Anthropology, 55: 141-151.

Kay R. (1984) On the use of anatomical features to infer foraging behavior in extinct primates. In: Rodman P.S. and Cant G.H. (eds.), "Adaptations for Foraging in Nonhuman Primates," Columbia University Press, New York, pp. 21-53.

Kay R. (1985) Dental evidence for the diet of Australopithecus. Annual Review of Anthropology, 14: 315-341.

Kay R.F. and Ungar P. (1997) Dental evidence for diet in some Miocene catarrhines on the effects of phylogeny on the interpretation of adaptation. In: Begun D.R., Ward C.V., and Rose M.D. (eds.), "Function, Phylogeny, and Fossils," Plenum Press, New York, pp. 131-152.

Liu W., Zheng L., and Jiang C. (2000) Statistical analyses of the metric data of hominoid teeth found in Yuanmou of China. Chinese Science Bulletin, 45: 936-942.

Liu W. Hlusko L., and Zheng L. (2001a) Morphometric analysis of hominoid lower molars found in Yuanmou of Yunnan Province, China. Primates, 42 (2): 123-134.

Liu W., Walker A., and Zheng L. (2001b) Three-dimensional morphometric analyses of hominoid lower molars from Yuanmou of Yunnan Province, China. Acta Anthropologica Sinica, 20: 163-177.

Lucas P.W., Corlett R.T., and Luke D.A. (1986) Postcanine tooth size and diet in anthropoid primates. Zeitschrift für Morphologie und Authropologie, 76 (3): 253-276.

Martin L.B. (1985) Significance of enamel thickness in hominoid evolution. Nature, 314: 260-263.

Pilbeam, D. (1997) Research on Miocene hominoids and hominid origins. The last three decades. In: Begun D.R., Ward C.V., and Rose M.D. (eds.), "Function, Phylogeny, and Fossils," Plenum Press, New York, pp. 13-28.

Schwartz J.H. (1997) Lufengpithecus and hominoid phylogeny: problems in delineating and evaluating 
phylogenetically relevant characters. In: Begun D.R., Ward C.V., and Rose M.D. (eds.), "Function, Phylogeny, and Fossils," Plenum Press, New York, pp. 363-388.

Schwartz G.T. (2000) Taxonomic and functional aspects of the patterning of enamel thickness distribution in extant large-bodied hominoids. American Journal of Physical Anthropology, 111: 221-244.

Schwartz G.T., Liu W., and Zheng L. (2002) Preliminary investigation of dental microstructure in the Yuanmou hominoid sample, Yunnan Province, China. Journal of Human Evolution (in press).

Smith R.J. (1996) Biology and body size in human evolution. Current Anthropology, 37: 451-481.

Teaford M.F. and Ungar P. (2000) Diet and the evolution of the earliest human ancestors. Proceedings of the National Academy of Sciences of the United States of America, 97 (25): 13506-13511.

Ungar P. (1996) Dental microwear of European Miocene catarrhines: evidence for diets and tooth use. Journal of Human Evolution, 31: 335-366.

Ungar P. and Kay R.F. (1995) The dietary adaptations of European Miocene catarrhines. Proceedings of the National Academy of Sciences of the United States of America, 92: 5479-5481.

Walker A. (1981) Diet and teeth. Philosophical Transactions of Royal Society of London, B, 292: 5764.

Ward S., Brown B., Hill A., Kelley J., and Downs W. (1999) Equatorius: a new hominoid genus from the middle Miocene of Kenya. Science, 285: 1382-1386.

White T.D., Suwa G., and Asfaw B. (1994) Australopithecus ramidus, a new species of early hominid from Aramis, Ethiopia. Nature, 371 (6495): 306-312.

Wood B.A. and Xu Q. (1991) Variation in the Lufeng dental remains. Journal of Human Evolution, 20: 291-311.

Woo J. (1957) Dryopithecus teeth from Keiyuan, Yunan Province. Vertebr Palasiatica, 1: 25-31.

Woo J. (1958) New materials of Dryopithecus teeth from Keiyuan, Yunan Province. Vertebr Palasiatica, 2: $38-43$.

Wu R. (1987) A revision of the classification of the Lufeng great apes. Acta Anthropologica Sinica, 6: 265-271.

Zhang X. (1987) New materials of Ramapithecus from Keiyuan, Yunnan. Acta Anthropologica Sinica, 6: 81-86.

Zheng L. and Zhang X.Y. (1997). Hominoid fossils. In: He Z.Q. (ed.), "Yuanmou Hominoid Fauna," Yunnan Science Press, Kunming, pp. 21-58.

Editor-in-Charge: Gen Suwa 